\title{
Arte contemporáneo en Málaga. Selección de artículos sobre exposiciones y artistas (1972-2015)
}

\author{
CAMACHO MARTÍNEZ, Rosario \\ Fundación Málaga, Málaga, 2016
}

Rosario Camacho realizó su primera crítica sobre arte contemporáneo un año antes de que yo naciera. Fue el texto dedicado a Joaquín de Molina el que inauguró el compendio de escritos -críticos y novelados- que la doctora Camacho guardó en la carpeta que hoy da título a esta publicación. Que el mismo artista, desconocido para algunos, sea el protagonista de la actual muestra en la Sala de Exposiciones de nuestra Universidad demuestra el olfato de Camacho, que ya percibió su valía hace más de cuarenta años.

Leer Arte Contemporáneo en Málaga. Selección de artículos sobre exposiciones y artistas (1972-2005), permite realizar un viaje al pasado por una ciudad que ha cambiado y sigue cambiando. En 2017 se inauguró, en el edificio de la Aduana, el deseado Museo de Málaga después de un largo periodo de espera; cada día las agendas de los periódicos ofrecen un número ingente de citas culturales en diferentes puntos de la capital, tanto en instituciones públicas como en espacios independientes. Pero no siempre fue así. En los años en los que arrancan los escritos de Rosario Camacho eran ellos, los intelectuales y los artistas, los que creaban el tejido cultural en una Málaga más sencilla pero, posiblemente, más auténtica. Al ayer pertenecen también algunos de los espacios expositivos que aparecen en el libro (unos desaparecidos y otros rehabilitados o reconvertidos, o ambos a la vez) haciendo posible el recuerdo de cuando el Museo Picasso albergaba el de Bellas Artes o cuando la Sala Moreno Villa acogía exposiciones como la de su buen amigo, Juan Antonio Ramírez. Aparte de la nostalgia que pueda suscitar, este recorrido recalca la importancia de la autora como cronista, como impulsora de un completo archivo para futuros investigadores del arte contemporáneo en nuestra ciudad. Solo los buenos historiadores del arte pueden hacer esto.

Con independencia de la elección de los artistas (algo que siempre responderá a un ejercicio subjetivo) los escritos críticos de Rosario Camacho son un ejemplo de coherencia; responden, en cada caso, a preferencias de una estudiosa con herramientas más que contrastadas para fundamen-

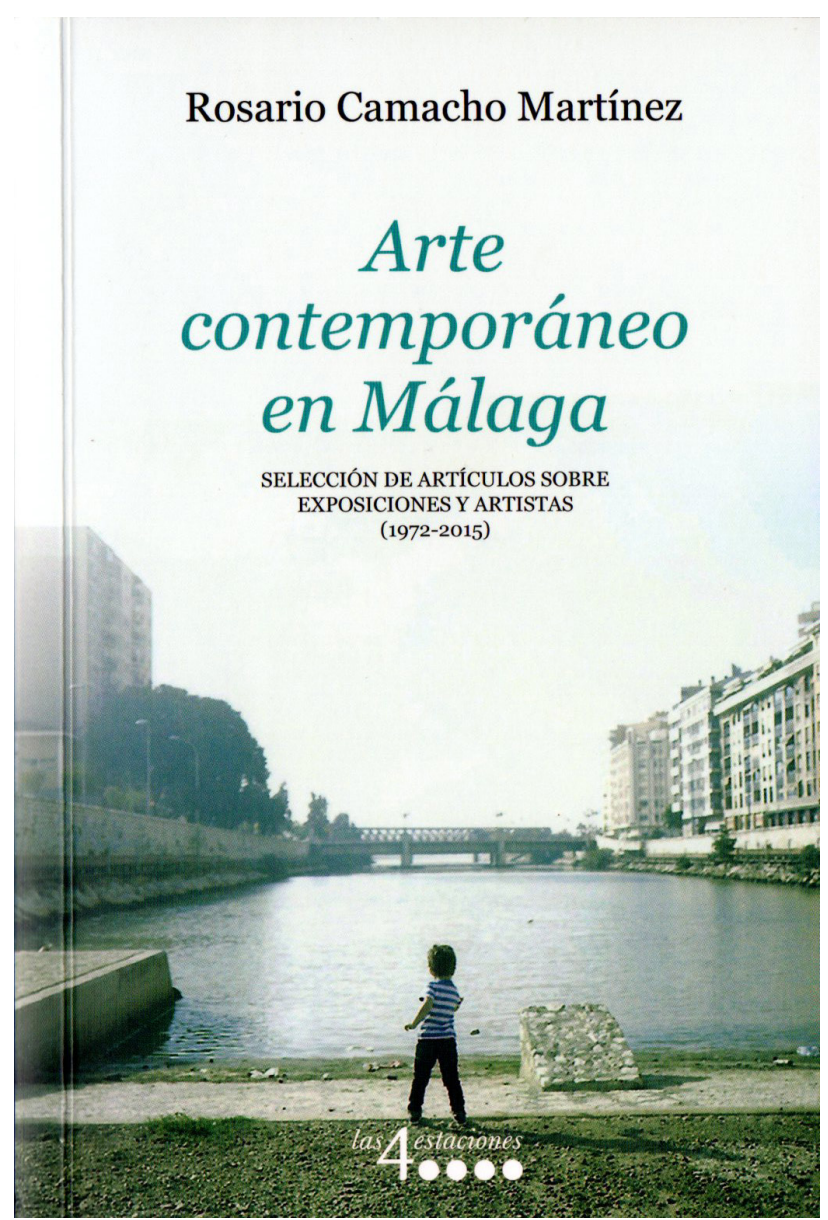

tar cada acontecimiento, cada obra. Resalta exposiciones colectivas tales como «Pintura actual en Málaga» (1974), «Grupo malagueño de artistas plásticos» (1976) o «Nueva figuración en el Museo de Málaga» (1979), e individuales de pintores y escultores que están aún en activo, como el enigmático Francisco Peinado, el incombustible Diego Santos o Paco Aguilar, al frente del Taller Gravura. Además de ensalzar las virtudes y destrezas de aquellos autores que elige, Camacho es descriptiva, analítica y, por qué no decirlo, rei- 
vindicativa si la situación lo merece, portando el estandarte de estricta justiciera cuando es consciente de que algo va mal, de que hay cosas que se pueden cambiar.

José Manuel Cabra de Luna, en el prólogo de Arte Contemporáneo en Málaga, asemeja los «episodios críticos» de la profesora Camacho a las antiguas postales de antaño, poseedoras de un valor incalculable por ser, cada una de ellas, única y especial. Las conferencias, los escritos en prensa, los textos en catálogos de exposición, los apuntes inéditos o las entregas al Boletín de Arte en el que se publica esta reseña, se convierten en la postal de José Hernández, en la de Suso de Marcos, en la de Ugly Child Arts, en la de Enrique Brinkmann o en la de Emilio Pettoruti. Un complejo collage que invita a conocer, de primera mano, cómo y cuándo germinó la modernidad en una ciudad como la nuestra.

María Jesús Martínez Silvente Universidad de Málaga 